\title{
O USO DE MAPAS COMO MEIO DE COMUNICAÇÃO E RESSIGNIFICAÇÃO DA EXPERIÊNCIA DO USUÁRIO NO TERRITÓRIO.
}

\author{
Taís Lagranha Machado \\ Universidade do Vale do Rio dos Sinos, Unisinos. \\ talagranha@gmail.com \\ Filipe Campelo Xavier da Costa \\ Universidade do Vale do Rio dos Sinos, Unisinos. \\ filipecxc@gmail.com
}

\begin{abstract}
Resumo: O presente trabalho se propõe a discutir e explorar os elementos dos processos de comunicação contidos em um mapa turístico. $\mathrm{O}$ artigo será desenvolvido a partir de uma revisão bibliográfica sobre o tema visando buscar insumos teóricos para a análise prática de um mapa de bairro da cidade de Porto Alegre. Por fim, como resultado, espera-se entender o mapa como um meio de comunicação e interação com potencial para ser utilizado pelo Design Estratégico devido sua capacidade de criar novos significados agregando valor ao território, além de ressignificar a experiência urbana do usuário.
\end{abstract}

Palavras-chave: design estratégico, design para experiência, mapıas.

\begin{abstract}
This paper aims to discuss and explore the elements of communication processes contained on a tourist map. Item will be developed from a literature review on the subject aimed theorists seek to practice analyzing a map of neighborhood in the city of Porto Alegre inputs. Finally, as a result, are expected to understand the map as a means of communication and interaction with the potential to be used by the Strategic Design because of their ability to create new meanings adding value to the territory, and reframe the urban user experience.
\end{abstract}

Keywords: strategic design, design experience, maps.

\section{INTRODUÇÃO}

O design estratégico opera âmbitos coletivos e complexos e coloca o designer como ator central do processo, capaz de interpretar a realidade e a partir de suas ações estratégicas, e gerar efeitos de sentido (2010, p.2). Esse agir estratégico permite organizar as peças de um quebra cabeças complexo para se propor novos significados, ou seja, as peças são organizadas em função desse novo sentido que se quer dar. Para Zurlo (2010, p.2) "a estratégia é tanto causa quanto efeito de um processo coletivo e 
interativo ato para modificar uma realidade", ele reforça a ideia de um trabalho em conjunto, do diálogo entre os diversos atores envolvidos, das intenções de viabilizar um plano traçado.

Cidades são sistemas complexos e o design estratégico vem se ocupando de operar nesse âmbito também. A abordagem estratégica, através dos modelos e instrumentos do próprio campo, sugerem um olhar transdisciplinar às cidades permitindo que o território seja entendido também como um sistema-produto. Para Reyes e Borba (2007), o design territorial tem como objetivo valorizar o mesmo e fazer com que ele ocupe "um novo posicionamento tanto em termos de imagem quanto de sustentabilidade econômica e social". Essas intervenções do design tem como finalidade gerar valor ao território, fortalecer potencialidades locais, propor envolvimento de todos os atores sociais desse sistema, criar novos cenários possíveis para o futuro e criar novos contextos projetando as imaterialidades relacionadas à experiência no território.

Dessa forma, destaca-se o papel do designer como um criador desses novos significados. Suas habilidades o tornam capaz de transmitir mensagens através dos artefatos que cria e nos meios em que circulam. (Franzato, 2011). A mensagem que é transmitida segue um plano traçado, ou seja, uma estratégia, e a intenção que está por trás deve ser traduzida pelo meio. O meio é um tradutor. Assim se dá a articulação do design estratégico com os temas do design, comunicação e significação.

Nesse contexto, o foco deste artigo é iniciar uma discussão sobre os processos midiáticos e de significação como geradores de sentido no território. Como objetivo, busca-se explorar e identificar os possíveis elementos dos processos de comunicação contidos em um mapa turístico. A abordagem será através de uma revisão bibliográfica sobre os conceitos trabalhados por Flusser (2007), Rodrigues (1999). Para isso, será feita a interpretação desses conceitos em um mapa projetado para o Bairro Cidade Baixa na cidade de Porto Alegre. Como resultado, busca-se entender mapa como um meio de comunicação e interação capaz de criar novos significados agregando valor ao território, construindo identidades e sentido de lugar além de resignificar a experiência urbana do usuárioma breve apresentação do tema, dos objetivos, noções do referencial teórico, da metodologia e alguns pontos marcantes do trabalho.

\section{METODOLOGIA E OBJETO DE ESTUDO: "COOL CITY MAPS"}

Para a análise e discussão crítica sobre o objeto, foi feita uma pesquisa bibliográfica sobre os conceitos de comunicação de Flusser (2007), além dos conceitos de expectativa e campo dos media de Rodrigues (1999).

Para objeto de análise, foi escolhido um mapa turístico impresso de Porto Alegre que faz parte do Projeto Cool City Maps (CCM). O mapa é aqui entendido como a materialização das intenções por trás desse projeto, além de representação do território. O projeto CCM é uma iniciativa privada, realizada por um estúdio de design com apoio de empresas e estabelecimentos comerciais da cidade, que busca promover a cultura local com forte apelo sustentável, desenvolvendo mapas das área mais atrativas da cidade. Com enfoque temático, turístico e cultural, o mapa indica percursos e pontos de relevância dessas áreas. O projeto está presente nos meios virtuais através de um site com informações gerais sobre o mesmo e uma página no facebook com divulgação de conteúdos ligados aos temas da sustentabilidade, cultura, turismo e dos pontos comerciais que apoiam o projeto. Dessa forma, o projeto se 
propõe à agregar valor as marcas apoiadoras e ao território, por meio do incentivo dessas novas práticas dentro desse sistema: mapa do bairro, ações sustentáveis e fortalecimento dos valores do projeto nas mídias sociais. Em outubro de 2012 foi lançada a primeira edição que compreende o bairro Cidade Baixa, Bom Fim e entorno (Figura 1). Além desse, já estão previstas mais duas edições, uma do bairro Moinhos de Vento e outra da Orla do Guaíba e seu entorno. Todas tem distribuição gratuita de cinco mil exemplares em pontos pré-estabelecidos e conveniados.

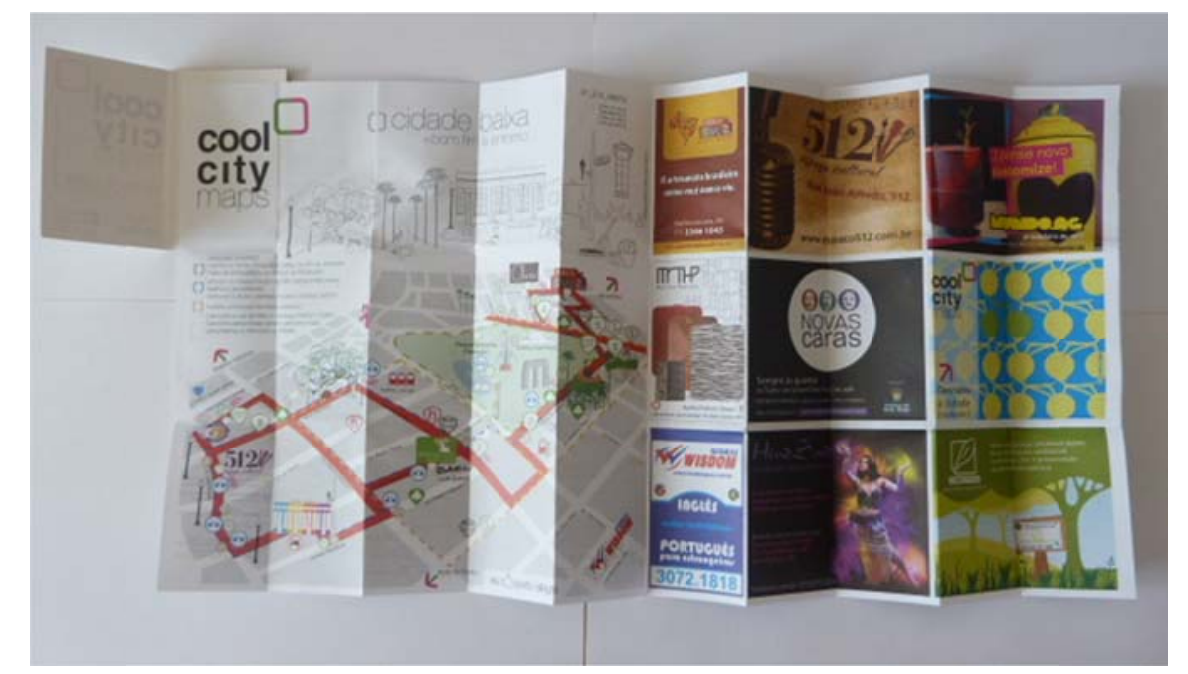

Figura 1 - fotografia do mapa Cool City Maps: Cidade Baixa e entorno. Fonte: autora.

O mapa foi projetado com dimensões pequenas para caber em um bolso, com $5.5 \mathrm{~cm}$ de largura e $8.5 \mathrm{~cm}$ de altura (Figura 2), consta de uma folha impressa frente e verso, dobrada com uma capa que o envolve e serve de suporte para anúncio.

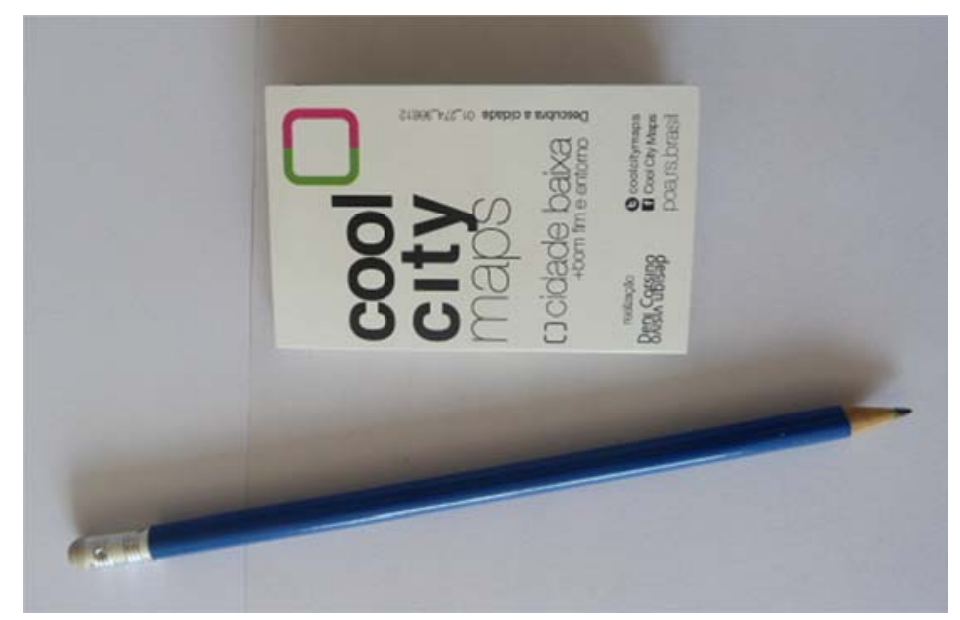

Figura 2 - fotografia do mapa Cool City Maps e relação de escala. Fonte: autora.

A página frontal é divida ao meio, à esquerda o espaço para o mapa perspectivado da região com detalhes, indicações de percursos e legenda, e à direita, a área reservada aos anúncios (Figura 3). O verso segue o mesmo padrão com um mapa geral da cidade 
de Porto Alegre e legenda detalhada dos espaços comerciais identificaldos no mapa do bairro (Figura 4).

O bairro é representado como uma imagem de fundo-figura, onde o formato dos seus quarteirões (em cinza) se destacam como "figuras" e as ruas são o fundo dessa imagem. A representação, tanto do mapa quanto de seus ícones, é feita em 3D e não em 2D como normalmente são feitas essas representações. Outros elementos que já fazem parte do imaginário coletivo estão presentes no mapa, dentre eles o Parque da Redenção, as palmeiras da Av. Oswaldo Aranha, os postes antigos da Rua João Alfredo, o túnel verde da Rua da República e alguns monumentos do parque como o Expedicionário e a fonte central. As únicas edificações são o Auditório Araújo Viana, o casario da travessa dos Venezianos e o Colégio Militar e Igreja Santa Terezinha, ambos, representados através das suas cúpulas.

O maior destaque do mapa é a indicação de um percurso, que liga o bairro principal com seu entorno, marcado em vermelho. Como percursos secundários, são sugeridos outros três relacionando cores diferentes (verde, azul e amarelo) com horários e tipos de atividades mais interessantes. O percurso verde sugere o passeio pela manhã e em finais de semana para aproveitar parques e cafés. O azul, indica como melhores horários o almoço e happy hour para curtir restaurantes, bares, danceterias além de indicá-lo como um percurso cultural com galerias, livrarias e teatros. Já o amarelo indica o horário comercial para o percurso em função da variedade de serviços encontrados. Juntamente com a legenda de percursos se encontra uma sugestão de que se explore os mesmos a pé ou bicicleta, para aproveitar melhor o bairro e suas peculiaridades.

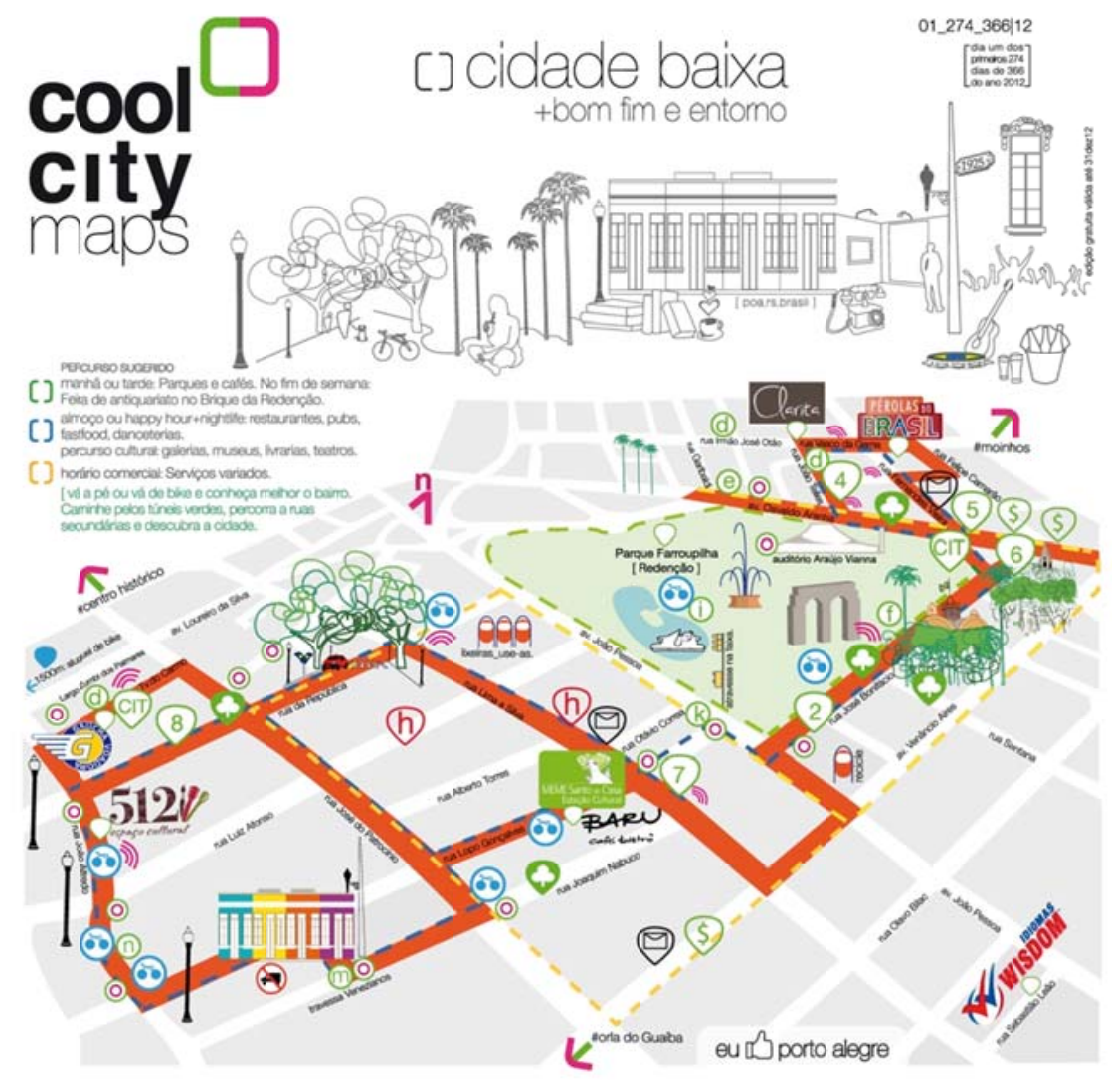

Figura 3 - Frente mapa Cool City Maps. Fonte: http://coolcitymaps.wordpress.com/ 
Sobre a imagem do mapa, alguns elementos da paisagem urbana e cultural recebem destaque como símbolos representativos do bairro (Figura 5), como por exemplo, ruas arborizadas que formam túneis verdes, chimarrão no parque, peças de antiquário (como simbolo da feira como atividade cultural) e shows (como simbolo de atividades artísticas).

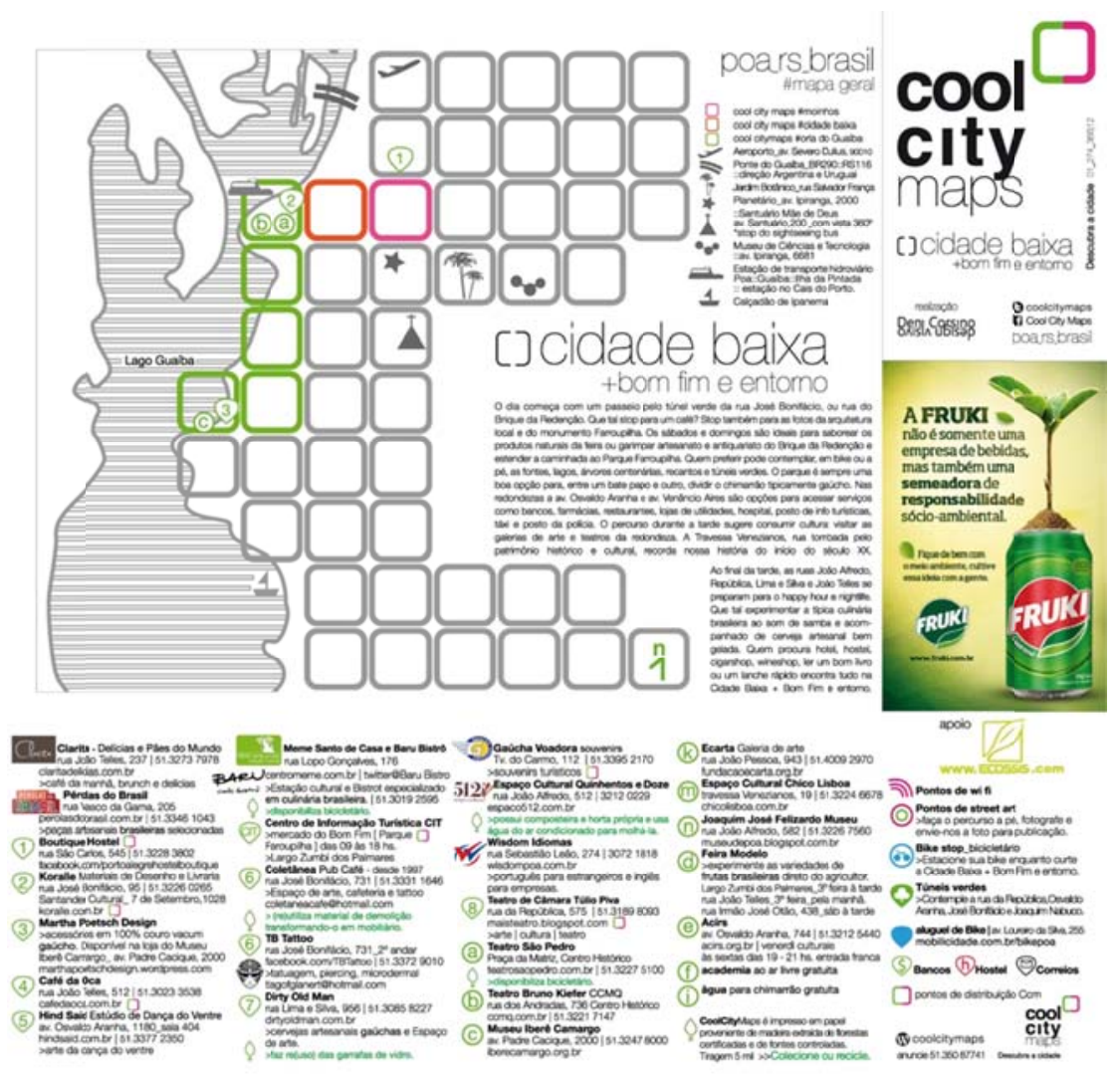

Figura 4 - Verso e legendas mapa Cool City Maps. Fonte: http://coolcitymaps.wordpress.com/

Figura 5 - recorte mapa, simbologia. Fonte: http://coolcitymaps.wordpress.com/

No verso está o mapa geral da cidade de Porto Alegre representado de maneira esquemática apenas para sinalizar o mapa referente a edição (ex.: Cidade Baixa e entorno) além de outros pontos de referências como aeroporto, estação de transporte hidroviário, Jardim Botânico e museus da cidade.

A legenda dos espaços comerciais oferece as informações básicas de endereço e contato e relações com atividades sustentáveis, caso o estabelecimento tenha. Alguns fazem a reutilização de garrafas de vidro, disponibilizam bicicletário, aproveitam 
material de demolição e outros tem composteira e horta própria para o preparo dos alimentos. Há também nas legendas, a indicação de pontos de street art, aluguel de bicicleta, bicicletários públicos e os túneis verdes que representam as ruas mais arborizadas da região que merecem contemplação. Por fim é apresentado um texto explicativo sobre o bairro, em forma de narrativa, que explora e simula as possíveis atividades no bairro durante um dia, da manhã à noite.

\section{ANÁLISE E DISCUSSÃO}

Os mapas são artefatos criados pelo homem com a função de representar o espaço territorial no qual ele vive. No entanto podem ser percebidos de outras formas, como suporte de uma metodologia para obtenção de dados ou como um meio que possibilita a transmissão de informações. Uma consiste em qualificar o mapa através da coleta e registro dos dados obtidos em levantamentos e observações de campo, como por exemplo, definir como essas informações coletadas serão representadas. A outra se refere à percepção dos dados representados em relação ao que eles comunicam. Nesse sistema, o mapa que representa informações adquiridas e as transmite através de símbolos e códigos, é um meio de comunicação. Neste artigo, parte-se do conceito de comunicação elaborado por Flusser (2007), que a define como armazenamento, processamento e distribuição de informação adquirida, para entender o mapa como um meio nesse processo.

Nota-se no mapa em questão (Figura 5) que as informações do local foram processadas de uma forma diferente para comunicar uma nova maneira de viver o bairro. O tipo de representação utilizada, tanto pela escrita quanto pelos símbolos, valoriza os aspectos mais urbanos do local assim como a prática de atitudes mais sustentáveis. Sob a ótica de Flusser, pode-se dizer que aqui se utiliza duas formas de comunicação em relação a estrutura, para se transmitir uma mesma mensagem: linha e superfície. Para o autor as linhas concebem os fatos que significam, pois transmitem com objetividade e nitidez a mensagem, que se pode ver como no recorte da legenda: "vá a pé ou vá de bike e conheça melhor o bairro. Caminhe pelos túneis verdes, percorra as ruas secundárias e descubra o bairro". Fica claro o sentido da mensagem, é o que está posto, e o receptor só precisa seguir a leitura até seu final para entendê-la. A superfície nesse caso é a imagem do mapa constituído por seu conjunto de símbolos. Em uma superfície, não há uma estrutura imposta para que se compreenda a mensagem. Nesse caso, os símbolos do mapa fazem o usuário entender que há um percurso principal (faixa vermelha) a ser percorrido e que este, dependendo do horário (linhas tracejadas coloridas) tem atrações distintas. Entende-se que pode ser percorrido de bicicleta ou a pé, já que são localizados diversos pontos de bicicletário, pontos de street art e ruas arborizadas ao longo do mesmo.

Dessa forma o conteúdo das mensagens, tanto pela escrita quanto por símbolos, incentiva o usuário do mapa (e da cidade) à interagir com os aspectos da paisagem local com forte apelo à uma experiência mais urbana. Nesse contexto, pode-se dizer que a composição das duas formas de comunicação no mesmo meio se complementaram uma a outra com o fim de fortalecer o discurso que está por trás. Ao retomar a citação de Flusser "a forma é condicionada pelo conteúdo e ela o condiciona", percebe-se que o mapa não representa o território com fidelidade, ao contrário disso, ele é construído para representar um novo significado, que por sua vez, está por trás do discurso. 
Como dito no início deste artigo, os mapas são construídos a partir de informações coletadas da realidade. No caso do objeto dessa análise onde se trata também de dados subjetivos, pode-se dizer que o mapa é um discurso resultado de diálogos existentes (Flusser), e por outro lado ele servirá, como discurso, de informação para outros diálogos. Se ele servirá de informação para novos diálogos, ele carrega o poder de gerar novos sentidos através de suas representações.

Nesse contexto, retoma-se os conceitos de Rodrigues (1999) acerca do campo dos media e experiência. $\mathrm{O}$ autor menciona a complexidade dos dispositivos técnicos de mediação atuais e sua capacidade de regular a percepção de mundo das pessoas às suas capacidades de simulação. Para Rodrigues (1999), no campo dos media o discurso é predominante, e em função dessa característica, o campo estabelece uma relação simbólica com a experiência. Ao delimitar o bairro como uma das áreas mais atrativas e "cool" da cidade ele exclui as outras áreas desse quadro. Dentro dessa delimitação, toda a informação transmitida pelo mapa deve estar organizada pela semântica, podendo assim se construir um cenário coerente para que o usuário espere ter a experiência pretendida nesse território. Para o autor, nesse campo o discurso deve estender sua atuação em relação aos valores de regras de comportamento para todos os tipos de linguagem envolvidas na produção de sentido para se construir o ambiente para a experiência. Neste caso de estudo, percebe-se a integração de todos os elementos do sistema (mapa + site + facebook) na construção do mesmo efeito de sentido. A mensagem a ser passada se adapta ao meio, de forma estratégica. O mapa foi trabalhado com foco na relação do usuário e experiência urbana, o site tem um apelo mais institucional e comercial e a página do Facebook trabalha na geração de notícias e conteúdos relacionados à ações e práticas de sustentabilidade, bem estar e dicas exclusivas do bairro.

O autor coloca os dispositivos técnicos como mediadores entre as pessoas e o mundo a ser vivido, onde a experiência do usuário é regulada pelas expectativas criadas pelo meio, neste caso, o mapa. Pode-se dizer que além do poder de gerar sentidos, os mapas também exercem um poder simbólico ao delimitar o quadro de experiência? Como se delimita esse quadro?

Nesse caso é possível dizer que o quadro de experiência é delimitado através de um discurso (na forma de símbolos no mapa) que prepara as expectativas do usuário para que ele possa vivenciá-la no território real. Então o mapa representa um território e simula uma nova experiência urbana focada na diversidade urbana, práticas sustentáveis e valorização da cultura local. Através do meio (o mapa), se estabelece um quadro das expectativas do usuário em relação ao que será vivenciado no território físico real, e não o simulado.

Além disso, entende-se que o mapa como um meio permite brechas para interação e interpretação do usuário a partir do momento que ele não registra apenas dados objetivos mas também os subjetivos. Quando se fala em experiência e expectativas (Rodrigues, 1999), faz-se uma relação direta com o conceito de habitus de Bourdie que, de certa forma, reforça a inexistência de um único sentido para interpretação dos significados. Como exemplo, o percurso indicado no mapa será sempre o mesmo, mas a experiência real, no território pode ser sempre diferente, pode ser uma mudança de olhar ao percorrer um mesmo percurso, o desvío por alguma rua ou calçada que podem resultar sempre em uma nova vivência nesse território. Deleuze e Guattarri (2000) complementam esse entendimento ao dizer que 
"o mapa é aberto, é conectável, em todas as suas dimensões, desmontável, reversível, suscetivel de receber modificações constantemente". Tampouco há um único sentido ou uma mesma entrada para experimentação. Em um mapa são sempre múltiplas entradas (Passos; Kastrup e Escóssia, 2012).

\section{CONCLUSÃO}

No decorrer deste artigo foram abordados temas relacionados aos processos de comunicação e significação no âmbito do design estratégico como elementos a serem explorados e aplicados para uma melhor compreensão da estratégia. Através desta reflexão, é possível sinalizar alguns pontos importantes e sugerir outros caminhos e abordagens para a continuidade dessa pesquisa.

No presente estudo, os conceitos de comunicação utilizados por Flusser assim como o campo dos media e os processos de produção de sentido trabalhados por Rodrigues, foram utilizados para interpretação e compreensão dos processos comunicacionais e de significação contidos em um mapa.

Dessa forma, foi possível entender o mapa como um meio de comunicação que se utiliza do poder da representação, através do uso de símbolos, para comunicar mensagens, (objetivas e subjetivas), transmitir valores além de sugerir novas práticas e comportamentos. Para que essa comunicação seja eficiente e seja uma operação da própria estratégia, utiliza-se da construção de narrativas, combinando as diferentes formas de comunicação (linha e superfície) como forma de fortalecer o discurso, que por sua vez, carrega esse novo significado que se busca gerar. Nesse contexto, destacase o papel do mapa com um meio tradutor e de ressignificação. Ele traduz a mensagem contida nos discursos e codifica as potencialidades do território, seus aspectos locais, culturais assim como práticas sustentáveis e de bem estar. Ao propor uma nova maneira de percorrer o bairro, novos pontos de referência no território, destaca aspectos da paisagem urbana e cultural, o mapa auxilia no processo de ressignificação da experiência urbana do usuário. Mas para que o mapa seja eficiente como um meio, deve-se pensar qual discurso está por trás dessa nova experiência que se propõe e é simulada por ele. Também faz parte desse desafio saber qual diálogo se quer promover, qual produção estética se quer realizar e dessa forma propor meios que permitam mais interação.

Diante das reflexões feitas neste trabalho, pode-se dizer que os mapas apresentam uma contemporaneidade em termos de comunicação pois permitem a interação dos usuários e possibilitam a interpretação das mesagens através das suas representações prossibilitando a formação de idéias e inserindo o mesmo na transformação do seu contexto e território.

Por fim, espera-se que as reflexões feitas neste trabalho sirvam de motivação para explorar outras abordagens acerca do uso de mapas como meio de comunicação. Dentre os diversos caminhos possíveis para a continuidade deste estudo está sua abordagem como uma possível metodologia para produção de conhecimento coletivo e mapeamento de aspectos subjetivos de territórios pelo Design Estratégico

\section{REFERÊNCIAS}

ZURLO, Francesco. Design Estratégico. Working Paper. 2010 
FLUSSER, Vilém. O mundo codificado: por uma filosofia do design e da comunicação. São Paulo: Cosac Naify, 2007.

FRANZATO, C. Design as Speculation. Design Philosophy Papers (Online), v. 9, p. sp-sp, 2011.

REYES, P. ; BORBA, G. Design Estratégico Aplicado ao Território. In: 4ํ Congresso Internacional de Pesquisa em Design, 2007, Rio de Janeiro. Anais do 40 Congresso Internacional de Pesquisa em Design, 2007.

KRIPPENDORFF, Klaus. The dialogical Reality of Meaning. In: The American Journal of Semiotics, Vol. 19, 1-4 (2003), 17- 34. Disponível em: http:/ repository.upenn.edu/asc papers/51.

MCLUHAN, Marshall. Os meios de comunicação como extensões do homem. São Paulo: Cultrix, 2007.

RODRIGUES, Adriano. A experiência, modernidade e campo dos media. 1999. Disponível em: http:www.bocc.uff.br/pag/Rodrigues-adriano-expcampmedia.pdf

CoolCityMaps. Mapa do Bairro Cidade Baixa+Bom Fim e entorno. Disponível em:<http://coolcitymaps.files.wordpress.com $>$.

Acesso em: 12 nov. 2012.

DEleuZE, G. \& GUATARRI, F. (1996). Mil Platôs: vol 1. São Paulo: Editora 34.

PASSOS, Eduardo; KASTRUP, Virgínia; ESCÓSSIA, Liliana da. Pistas do Método da cartografia: Pesquisa-intervenção de subjetividade. Porto Alegre: Sulina, 2012. 207p. 